\title{
Effects of phosphodiesterase 4 inhibition on bleomycin-induced pulmonary fibrosis in mice
}

\author{
Sergey Udalov'1, Rio Dumitrascu', Soni S Pullamsetti1,2, Hamza M Al-tamari1', Norbert Weissmann', \\ Hossein A Ghofrani1 ${ }^{1}$, Andreas Guenther1, Robert Voswinckel1,2, Werner Seeger1,2, Friedrich Grimminger ${ }^{1}$ and \\ Ralph T Schermuly*1,2
}

\begin{abstract}
Background: Pulmonary fibrosis (PF) is a group of devastating and largely irreversible diseases. Phosphodiesterase (PDE) 4 is involved in the processes of remodeling and inflammation, which play key role in tissue fibrosis. The aim of the study was, therefore, to investigate the effect of PDE4 inhibition in experimental model of PF.

Methods: PF was induced in C57BL/6N mice by instillation of bleomycin. Pharmacological inhibition of PDE4 was achieved by using cilomilast, a selective PDE4 inhibitor. Changes in either lung inflammation or remodeling were evaluated at different stages of experimental PF. Lung inflammation was assessed by bronchoalveolar lavage fluid (BALF) differential cell count and reverse transcription quantitative polymerase chain reaction (RT-GPCR) for inflammatory cytokines. Changes in tissue remodeling were evaluated by pulmonary compliance measurement, quantified pathological examination, measurement of collagen deposition and RT-qPCR for late remodeling markers. Survival in all groups was analyzed as well.

Results: PDE4 inhibition significantly reduced the total number of alveolar inflammatory cells in BALF of mice with bleomycin-induced PF at early fibrosis stage (days 4 and 7). Number of macrophages and lymphocytes, but not neutrophils, was significantly reduced as well. Treatment decreased lung tumor necrosis factor (TNF)-a mRNA level and increased mRNA level of interleukin (IL)-6 but did not influence IL-1 $\beta$. At later stage (days 14 and 24) cilomilast improved lung function, which was shown by increase in lung compliance. It also lowered fibrosis degree, as was shown by quantified pathological examination of Hematoxilin-Eosin stained lung sections. Cilomilast had no significant effect on the expression of late remodeling markers such as transforming growth factor (TGF)- $\beta 1$ and collagen type la1 (COL(I)a1). However, it tended to restore the level of lung collagen, assessed by SIRCOL assay and Masson's trichrome staining, and to improve the overall survival.

Conclusions: Selective PDE4 inhibition suppresses early inflammatory stage and attenuates the late stage of experimental pulmonary fibrosis.
\end{abstract}

\section{Background}

Pulmonary fibrosis represents a group of devastating and largely irreversible human interstitial lung diseases having only limited treatment options. The disease is characterized by chronic interstitial inflammation, abnormal function of interstitial fibroblasts and deposition of excessive amounts of collagen, altogether leading to severe tissue remodeling [1]. Pathological changes are accompanied by elevated expression of cytokines TNF- $\alpha$,

\footnotetext{
* Correspondence: ralph.schermuly@mpi-bn.mpg.de

1 University of Giessen, Department of Internal Medicine, Giessen, Germany Full list of author information is available at the end of the article
}

IL-1 $\beta$, IL-6, growth factors and matrix metalloproteases (MMPs) [2-4]. The most common experimental model of human PF is bleomycin-induced PF in mice. It is characterized by inflammatory and remodeling stages, which allows studying different aspects of the disease [5].

Phosphodiesterases are a superfamily of enzymes that hydrolyze cAMP and/or cGMP and thereby regulate the intracellular levels of second messengers [6]. Members of PDE4 family (E.C. 3.1.4.17) are cAMP-specific PDEs composed of number of isoforms and are highly represented in the lung [7-10]. As a component of cAMP/protein kinase A (PKA) pathway PDE4 plays direct role in 
cell proliferation, differentiation and migration through regulation of the cAMP level [11-13]. Finally, PDE4 represents the major cAMP-hydrolyzing enzyme in monocytes, lymphocytes and neutrophils and its activation is required for inflammatory response $[8,14,15]$.

For these reasons, PDE4 inhibitors were suggested for treatment of several lung diseases as new anti-inflammatory and anti-remodeling agents [16]. Our group has previously demonstrated that PDE3/4 inhibitor attenuates migration of pulmonary artery smooth muscle cells (PASMCs) in vitro and reverses pulmonary vascular remodeling in vivo [17]. PDE4 inhibitor cilomilast was also shown to suppress the release and activation of MMP-1 and MMP-9 from lung fibroblasts, which are known to be involved in PF progression [18]. Furthermore, cilomilast and other PDE4 inhibitors were demonstrated to inhibit lung TNF- $\alpha$ and TGF- $\beta$ release, as well as neutrophil influx in vivo [19-21]. Finally, treatment of experimental chronic colitis with PDE4 inhibitor rolipram resulted in decreased collagen deposition as well as TNF- $\alpha$ and TGF- $\beta$ content in the tissue [22].

In the present study we hypothesized that PDE4 inhibitors are able to modulate both inflammatory response and tissue remodeling. The aim of the study was, therefore, to investigate the effects of selective PDE4 inhibitor on different aspects of experimental PF in vivo.

\section{Methods}

Animals

Adult male 5-6 weeks-old C57BL/6N mice weighting 19$21 \mathrm{~g}$ were obtained from Charles River Laboratories (Germany). Animals were housed under room temperature and 12/12-hour light/dark cycle with free access to food and water. All experiments were performed in accordance with the National Institutes of Health Guidelines on the Use of Laboratory Animals. Both the University Animal Care Committee and the Federal Authorities for Animal Research of the Regierungspraesidium Giessen (Hessen, Germany) approved the study protocol.

\section{Bleomycin administration and treatment groups}

At day 0 mice were given anesthesia with isofluran (Baxter, Germany) followed by random orotracheal instillation of bleomycin (Sigma, Germany) or sterile saline $(0.9 \% \mathrm{NaCl})$ with the mouse nose kept pinched. Bleomycin dissolved in sterile saline was given at the dose of 2.8 units $/ \mathrm{kg}$. Animals were assigned to the following groups 1) "saline", 2) "bleo+ctrl" and 3) "bleo+cilo". "Saline" group received instillation of sterile saline at day 0 and was given vehicle alone ( $2 \%$ aqueous methylcellulose solution). Mice in "bleo+ctrl" group received instillation of bleomycin at day 0 and were given vehicle alone. Mice in "bleo+cilo" group received instillation of bleomycin at day 0 and were treated once a day with $50 \mathrm{mg} / \mathrm{kg}$ cilomilast (SB207499 or Ariflo', [c-4-cyano-4-(3-cyclopentyloxy-4- methoxyphenyl)-r-l-cyclohexane carboxylic acid]) (Nycomed, Germany), suspended in vehicle. Solutions were administered per os via feeding needle, all in the same manner. Treatment in all groups started at day 0 and lasted till the end of experiment, i.e. for 4, 7, 14 or 24 days.

\section{Bronchoalveolar lavage fluid cell count}

At days 4 and 7 after bleomycin instillation mice were euthanized by injecting a lethal dose of pentobarbital. Lungs were flushed three times with $0.5 \mathrm{ml}$ ice cold PBSEDTA, recovered fluid was centrifuged and cell pellet was re-suspended in $1 \mathrm{ml}$ of ice-cold saline. Total cell count was performed using Neubauer counting chamber (depth $0.1 \mathrm{~mm}, 0.0025 \mathrm{~mm}^{2}$; Optik Labor, Germany). For differential cell count cells in constant volume of $0.2 \mathrm{ml}$ of PBS were transferred to a glass slide with Cytospin-3 centrifuge (Shandon Scientific Ltd, UK) and stained with May Gruenwald/Giemsa. Numbers of macrophages, neutrophils and lymphocytes were determined by counting on light microscope (Q550IW; Leica, Germany) among 100 of total cells. These data were then extrapolated to number of cells per milliliter.

\section{Lung compliance and histological examination}

At days 14 and 24 after bleomycin instillation mice were subjected to lung compliance measurement as described previously [23]. Briefly, animals were anesthetized with i.p. injection of ketamin/xylacinehydrochloride (Bayer, Germany). Trachea was canulated, mice were placed in the chamber and connected to the instrument. Volume of $0.3 \mathrm{ml}$ and pressure of $3 \mathrm{kPa}$ were set for calculating compliance as a ratio of volume to pressure $(\mathrm{ml} / \mathrm{kPa})$. Lungs of mice were isolated at the same time points. Four right lobes were inflated with $4.5 \%$ formaldehyde solution at constant pressure and fixated as described elsewhere. After dehydration in tissue processor lung lobes were individually embedded in paraffin, sectioned at $3 \mu \mathrm{m}$ on microtome (all instruments from Leica, Germany), mounted on glass slides and stained either with Hematoxilin-Eosin or Masson's trichrome according to standard protocols. For histological assessment, HematoxilinEosin-stained slides were scanned with light microscope (Leica, Germany) at 100× magnification yielding 50-100 images for each lobe (up to 300 per animal). Each of the images was reviewed and degree of fibrosis was assigned according to Ashcroft's fibrosis score system [24] with slight modifications: normal lung was referred to as score "0" while score "6" represented maximal degree of pathological changes.

\section{Collagen assay}

Level of collagen in lung tissues was determined by SIRCOL collagen assay (Biocolor Ltd., UK) according to manufacturer's instructions. Briefly, left lung lobes were 
homogenized and collagen was solubilized in $0.5 \mathrm{M}$ acetic acid. Extracts were incubated with Sirius red dye and absorbance was determined at $540 \mathrm{~nm}$ with spectrophotometer Infinite M200 (Tecan, Austria). Amount of collagen was expressed in $\mu \mathrm{g} / \mathrm{g}$ of wet tissue.

\section{Survival analysis}

Survival of mice for each treatment group was expressed in percent of animals left of original number at the specific time points of the experiment. Mice were followed up for 24 days.

\section{RNA isolation and CDNA synthesis}

For RNA extraction left lung lobes were isolated and snap-frozen in liquid nitrogen. Tissues were homogenized with Precellys 24 homogenizer (Bertin Technologies, France) in $0.5 \mathrm{ml}$ of TRIzol reagent (Invitrogen, USA) and RNA was extracted according to standard protocol. cDNA synthesis was carried out with ImProm-II ${ }^{\mathrm{m}}$ Reverse Transcription System (Promega, USA) according to manufacturer's instruction.

\section{Real-time polymerase chain reaction}

For quantitative real-time $\mathrm{PCR}$ analysis, cDNA was amplified with Platinum ${ }^{\circ}$ SYBR ${ }^{\circ}$ Green qPCR SuperMixUDG mix (Invitrogen, USA). Specific PCR primers (Metabion, Germany), designed to anneal to adjacent exons to exclude possible amplification from genomic DNA, were: mouse $\beta$-actin 5'-CTCTAGACTTCGAGCAGGAGATG3' (forward) and 5'-CACTGTGTTGGCATAGAGGTCTT-3' (reverse); mouse TNF- $\alpha$ 5'-GCCTATGTCTCAGCCTCTTCTC-3' (forward) and 5'-CACTTGGTG GTTTGCTACGA-3' (reverse); mouse IL-1 $\beta$ 5'-GAGCACCTTCTTTTCCTTCATCT-3' (forward) and 5'GATATTCTGTCCATTGAGGTGGA-3' (reverse); mouse IL6 5'-TCAATTCCAGAAACCGCTATGAA-3' (forward) and 5'-CACCAGCATCAGTCCCAAGAA-3' (reverse); mouse COL(I)a1 5'-AGCTTTGTGGACCTCCGGCT-3' (forward) and 5'-ACACAGCCGTGCCATTGTGG-3' (reverse); mouse TGF- $\beta 1$ 5'-AACCCCCATTG CTGTCCCGT-3' (forward) and 5'-CCTTGGTTCAGCCACTGCCG-3' (reverse). Quantitative real-time PCR was carried out in Srtratagene Mx3000P ${ }^{\mathrm{mw}}$ qPCR system (Stratagene, USA) and data were analyzed with accompanying software. The instrument was programmed as follows: denaturation, $95^{\circ} \mathrm{C}$ for $10 \mathrm{~min}$; 40 cycles with denaturation at $95^{\circ} \mathrm{C}$ for $30 \mathrm{~s}$, annealing at $58-60^{\circ} \mathrm{C}$ for 30 $\mathrm{s}$ and extension at $72^{\circ} \mathrm{C}$ for $30 \mathrm{~s}$. To ensure that specific single product is generated dissociation curves were evaluated. Relative expression levels were calculated as $\Delta \mathrm{Ct}$ values by normalizing $\mathrm{Ct}$ values of target genes to $\mathrm{Ct}$ values of $\beta$-actin as previously described [17].

\section{Statistical analysis}

All data are presented as means +/- SEM. The differences among groups were assessed by one-way Analysis of Vari- ance (ANOVA) test and Student-Newman-Keuls posttest for multiple comparisons. A $p$-value less than 0.05 was considered statistically significant.

\section{Results \\ Effect of PDE4 inhibition on alveolar inflammatory cells content}

To assess the effect of cilomilast on lung inflammation, BALF was collected at early stage of bleomycin-induced fibrosis from healthy mice treated with vehicle and mice that received bleomycin and treated either with cilomilast or vehicle. Total number of alveolar inflammatory cells was dramatically increased by instillation of bleomycin (Fig. 1). In contrast, number of cells was significantly lower in groups that received cilomilast, both at 4 and 7 days ( $\mathrm{p}<0.001$ and $\mathrm{p}<0.05$ respectively).

To further evaluate the action of cilomilast on different inflammatory cell types differential cell count was performed (Fig. 1). As expected, all cell types were highly present in alveolar space after bleomycin instillation, with the highest increase in number of lymphocytes and neutrophils. Number of macrophages and lymphocytes was significantly decreased by cilomilast both at 4 days $(\mathrm{p}<$ 0.001 for both cell types) and 7 days ( $p<0.05$ and $\mathrm{p}<0.01$ for macrophages and lymphocytes respectively). Number of neutrophils, however, remained unchanged.

\section{Effect of PDE4 inhibition on lung inflammatory markers}

To evaluate the expression of major inflammatory markers after cilomilast treatment, lung homogenate RTqPCR was carried out at the same time points as for BALF cell count. At 4 and 7 days after bleomycin instillation lung expression of TNF- $\alpha$, IL- $1 \beta$ and IL- 6 was significantly elevated compared to animals that received saline (Fig. 2). Treatment with cilomilast significantly lowered TNF- $\alpha$ mRNA level ( $\mathrm{p}<0.001$ at 4 and 7 days) and increased IL- 6 mRNA level ( $p<0.05$ at 4 and 7 days) compared to mice treated with vehicle. No significant change, however, was observed in the level of IL-1 $\beta$.

\section{Effect of PDE4 inhibition on lung function and pathology}

To examine the effect of cilomilast on tissue remodeling at late stage fibrosis, lung compliance and pathological changes were evaluated in animals treated either with cilomilast or vehicle, as well as in mice received instillation of saline and treated with vehicle. Pulmonary compliance (Fig. 3) was significantly lower in mice with bleomycininduced fibrosis both at 14 and 24 days, which shows a typical decrease in elasticity of the lung tissue. Treatment with cilomilast partially restored impaired lung function with improvement being significant at 14 days $(\mathrm{p}<0.05)$, compared to mice treated with vehicle alone.

Similarly, pathological changes estimated by means of microscopy followed by scoring (Fig. 3) evidenced significant distortion of lung architecture in mice with bleomy- 

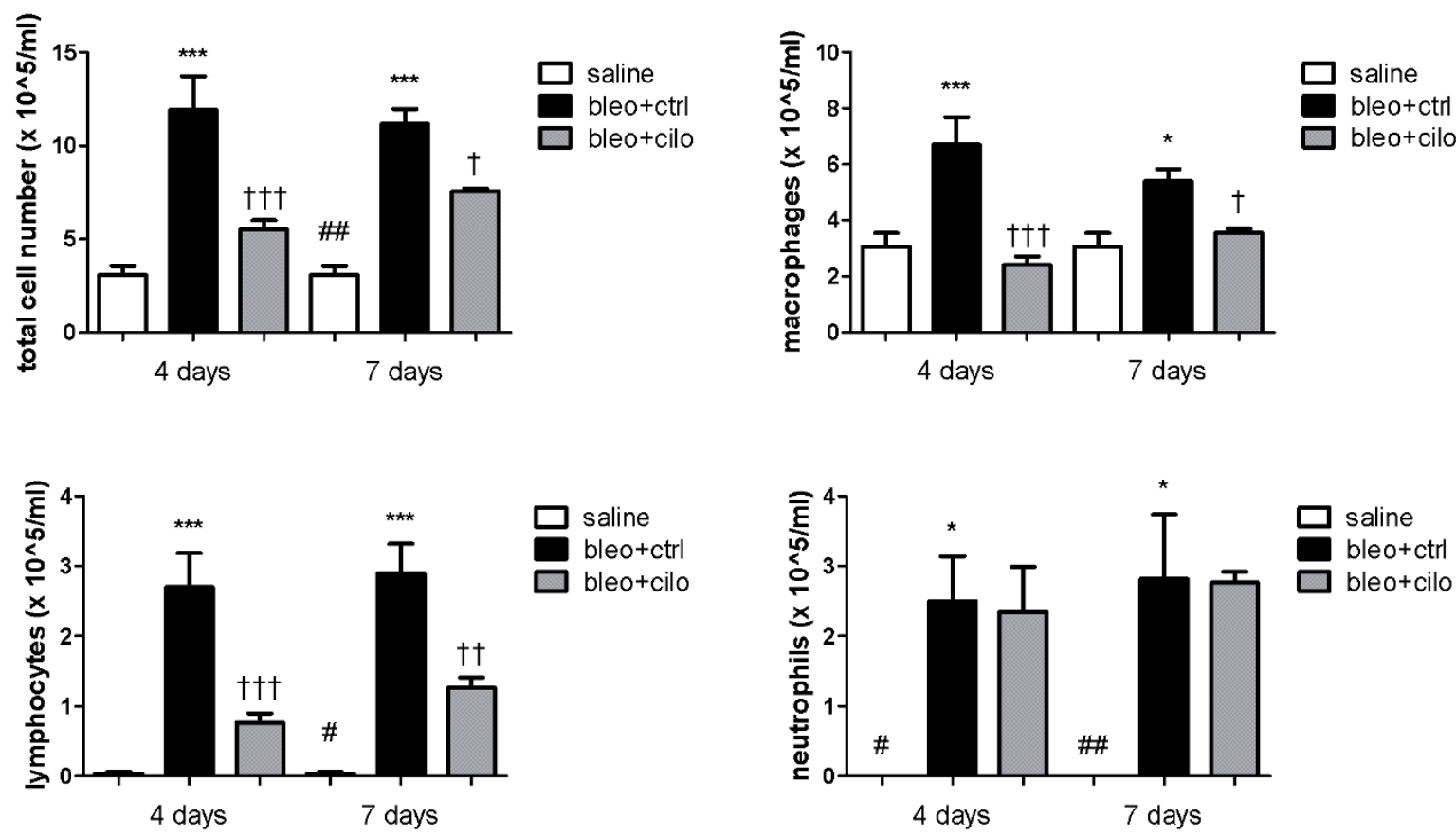

Figure 1 PDE4 inhibition suppresses alveolar inflammation at early stage fibrosis. Total cell number, number of macrophages, lymphocytes and neutrophils in bronchoalveolar lavage fluid (BALF) of healthy controls treated with vehicle ("saline") and in mice suffering from fibrosis and treated either with vehicle ("bleo+ctrl") or cilomilast ("bleo+cilo") at days 4 and 7 after bleomycin instillation. Values are presented as means $\pm S E M, n=6 .{ }^{*}$ saline vs. bleo+ctrl $\left({ }^{*} p<0.05,{ }^{* * *} p<0.001\right)$, + bleo+ctrl vs. bleo+cilo $(+p<0.05,+\dagger p<0.01,+\dagger+p<0.001)$, \# saline vs. bleo+cilo $(\# p<0.05$, \#\# $p<0.01)$.

cin-induced fibrosis. Degree of fibrosis was lower in lungs of animals treated with PDE4 inhibitor compared to ones treated with vehicle only, reaching significance at day 24 $(\mathrm{p}<0.05)$.

Representative images of lung sections stained with Hematoxilin-Eosin (Fig. 4) demonstrate the degree of mentioned pathological changes quantified by fibrosis scoring.

\section{Effect of PDE4 inhibition on lung collagen content and remodeling markers}

Collagen content in the lungs was estimated by SIRCOL assay, Masson's trichrome staining and RT-qPCR for COL(I) $\alpha 1$ at day 24 or at day 14 and 24 after bleomycin administration in all treatment groups. Total collagen assay ( $\mu \mathrm{g} / \mathrm{g}$ tissue) showed significant 2-fold increase among mice received bleomycin (Fig. 5), which was confirmed by Masson's trichrome staining (Additional file 1). Treatment with cilomilast tended to reduce collagen content in the lungs, although the effect was rather moderate. In contrast, virtually no effects were observed at mRNA level of COL(I) $\alpha 1$ at particularly at day 24 (Additional file 2). Similarly to collagen, cilomilast had no significant effect on mRNA level of TGF- $\beta 1$ (Additional file 3).

\section{Effect of PDE4 inhibition on survival}

General effect of cilomilast on the course of experimental PF was evaluated by survival analysis (Fig. 6). Inhibition of PDE4 had beneficial effect on survival as was seen at the end of experiment (day 24) in the group that received cilomilast compared to one treated with vehicle alone. No mortalities were observed in the group that received sterile saline.

\section{Discussion}

In the present study we have demonstrated beneficial anti-inflammatory effects of selective PDE4 inhibitor cilomilast at inflammatory stage of experimental PF, including reduction in BALF cell numbers, suppression of TNF$\alpha$ and stimulation of IL- 6 expression. We have also demonstrated improvements in lung function and pathological changes at later fibrosis stages. Finally, we have showed that treatment with PDE4 inhibitor tends to reduce lung collagen content and to improve the overall survival of the animals with bleomycin-induced PF.

Both human PF and bleomycin-induced PF in mice are characterized by chronic interstitial inflammation $[1,5]$. Given that PDE4 is the major cAMP-hydrolyzing enzyme in inflammatory cells and that it is necessary for developing of inflammatory response $[8,14,15,25]$, several studies 

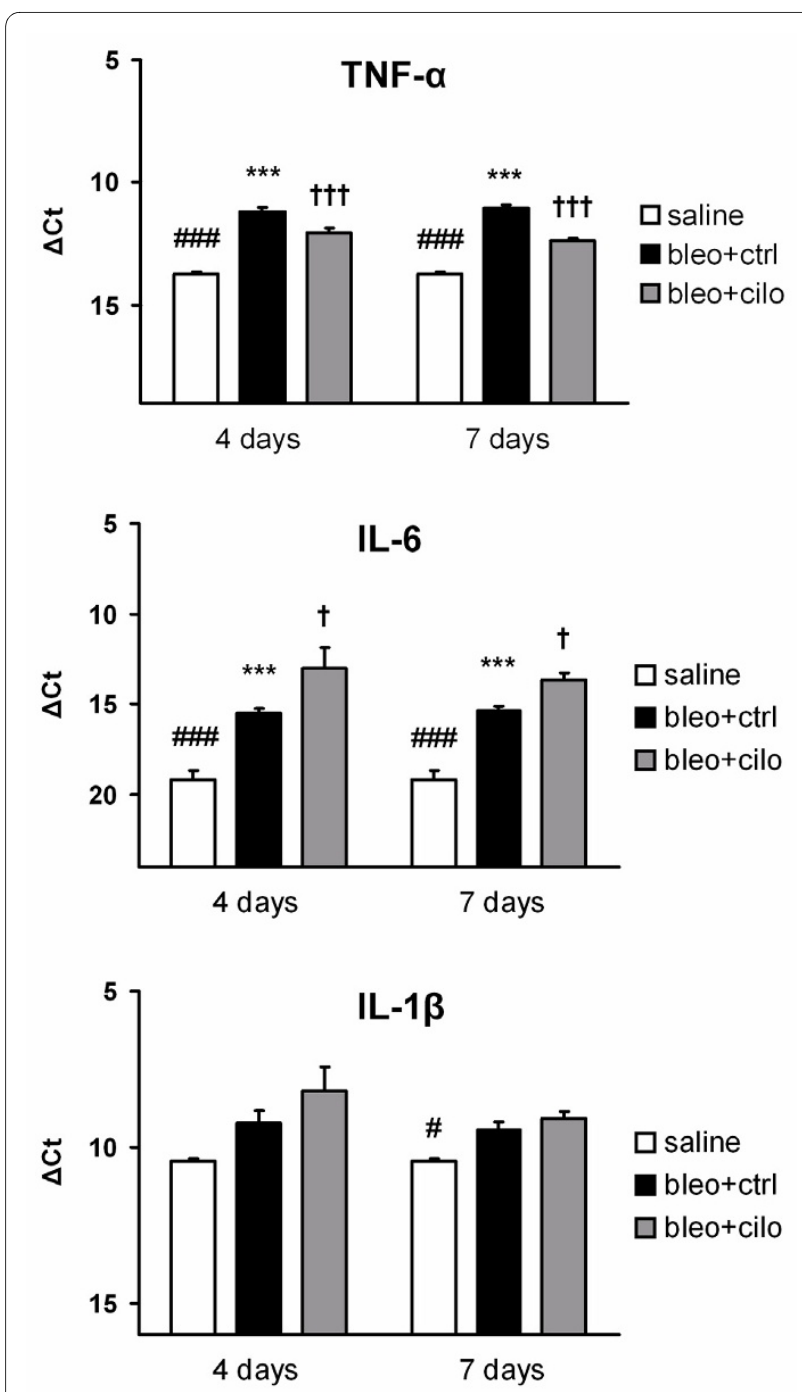

Figure 2 Effect of PDE4 inhibition on lung inflammatory markers at early stage fibrosis. TNF- $a, \mathrm{IL}-6$ and IL-1 $\beta$ mRNA levels in healthy controls treated with vehicle ("saline") and in mice suffering from fibrosis and treated either with vehicle ("bleo+ctrl") or cilomilast ("bleo+ciIo") at days 4 and 7 after bleomycin administration. RT-qPCR data are normalized to $\beta$-actin expression and presented as $\triangle C$ t values \pm SEM, $\mathrm{n}=6$. ${ }^{*}$ saline vs. bleo+ctrl (*** $\left.<<0.001\right)$, $\dagger$ bleo+ctrl vs. bleo+cilo $(\dagger p$ $<0.05$, t十† $p<0.001$ ), \# saline vs. bleo+cilo (\# $p<0.05$, \#\#\# $p<0.001$ ).

showed beneficial effect of PDE4 inhibitors on such inflammatory diseases as asthma and chronic obstructive pulmonary disease (COPD) [16]. Thus, we suggested positive effect of PDE4 inhibition on inflammatory component of PF.

Indeed, cilomilast was the most potent at early stage (days 4 and 7) of bleomycin-induced PF, when inflammation is the major characteristic of the pathological process [5]. Total number of alveolar inflammatory cells in BALF of treated mice was significantly reduced, as well as number of macrophages and lymphocytes. These results are consistent with the fact that PDE4 expression is induced by inflammatory stimulus and that it mediates activation and proliferation of T-cells and function of macrophages [25-28]. In turn, macrophages represent the major inflammatory cell type in alveolus, thereby strongly influencing total cell count values [29,30].

Neutrophils also play important role in pathological tissue remodeling damaging the lung parenchyma by proteolytic enzymes. Indeed, IPF patients have higher numbers of neutrophils and higher concentrations of granule enzymes, such as neutrophil elastase, myeloperoxydase, collagenase and lactoferrin in BALF, plasma and lung tissue [30,31]. Ariga et al. described direct involvement of PDE4 into neutrophil recruitment and chemotaxis [32] and Corbel et al. showed a decrease in neutrophils release by selective PDE4 inhibitor piclamilast in a murine model of LPS-induced acute lung inflammation [21]. However, we could not observe the significant suppression of neutrophil influx by cilomilast in our experimental setup. This inconsistency can be explained by early (hours) time-points used in acute lung inflammation experiments. The time-points used in the present work ( 4 and 7 days) were chosen to more closely mimic the inflammatory component of PF. But at the same time they are known to correspond to the peak in the neutrophil influx, therefore making it more difficult to achieve the significant improvement [33]. Another explanation might be the differential ability of the compounds to affect particular cell types and release of mediators. For instance, one study showed differential effect of several PDE4 inhibitors on neutrophils and TNF-a release, indeed revealing some limitations of cilomilast [20].

To find if general suppression of inflammatory cells release was also reflected in lung inflammatory cytokines expression, expression of TNF- $\alpha$, IL-1 $\beta$ and IL- 6 was analyzed at the same time points as the cell count experiments were done. These markers are upregulated in the lungs of both humans and mice with PF and are the canonical cytokines expressed at first days 4-7 of experimental PF [2-5]. We demonstrated significantly lower TNF- $\alpha$ expression in the lungs of mice treated with cilomilast compared to those received placebo. Taking into account lower numbers of BALF macrophages after cilomilast treatment it was expected to see downregulation of TNF- $\alpha$ as macrophages represent one of the major sources of this cytokine [2]. Similar effects of cilomilast were also shown by other authors [19]. In addition, significantly higher expression of IL-6 was observed in cilomilast-treated animals, compared to controls. This cytokine is known to exert anti-inflammatory effects and its exogenous administration was shown to decrease BALF cell recruitment, macrophage-mediated TNF-a production and lung hydroxyproline content in experimental pneumonitis in mice [34]. We suggest, therefore, that increase in IL-6 expression caused by cilomilast accompanies the 

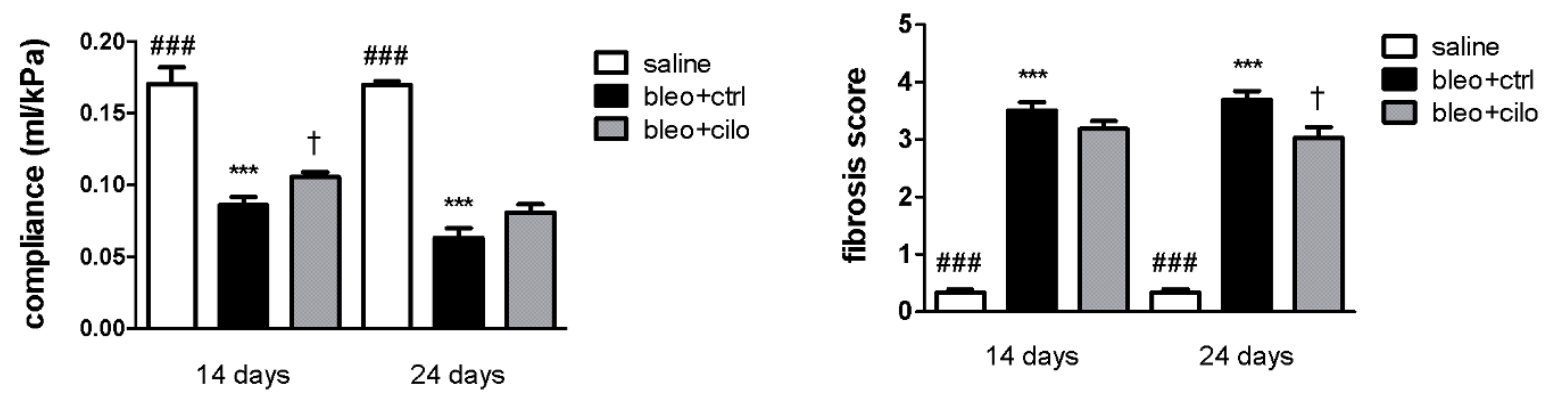

Figure 3 PDE4 inhibition improves lung function and attenuates tissue remodeling at late stage fibrosis. Lung compliance and fibrosis scores in healthy controls treated with vehicle ("saline") and in mice suffering from fibrosis and treated either with vehicle ("bleo+ctrl") or cilomilast ("bleo+cilo") at days 14 and 24 after bleomycin administration. Values are presented as means $\pm \mathrm{SEM}, \mathrm{n}=9 .{ }^{*}$ saline vs. bleo+ctrl $\left({ }^{* * *} \mathrm{p}<0.001\right)$, + bleo+ctrl vs. bleo+cilo († $p<0.05)$, \# saline vs. bleo+cilo (\#\# $p<0.001)$.

general suppression of inflammatory cell influx and TNF$\alpha$ content in the lung. Interestingly, cilomilast did not change lung expression of IL-1 $\beta$. However, it was previously reported that PDE4 inhibitors have little or no effect on production of this cytokine [35]. Taken together, we suggest that PDE4 inhibition suppresses lung inflammation via modulation of TNF- $\alpha$ and IL- 6 .

Besides inflammation, PF is characterized by tissue remodeling and accumulation of extracellular matrix components. This ultimately results in impairment of gas exchange due to thickened interstitium and in worsening of lung mechanical properties due to increasing stiffness of the tissue [1]. As expected, decreased pulmonary compliance, higher fibrosis degree and higher lung collagen level were observed at days 14 and 24 in mice that received instillation of bleomycin. Progression of fibrosis is illustrated by lower compliance and higher fibrosis score at day 24 compared to day 14. Typical manifestations of bleomycin-induced PF, such as patchy pattern and interstitial inflammation were also observed. In turn,

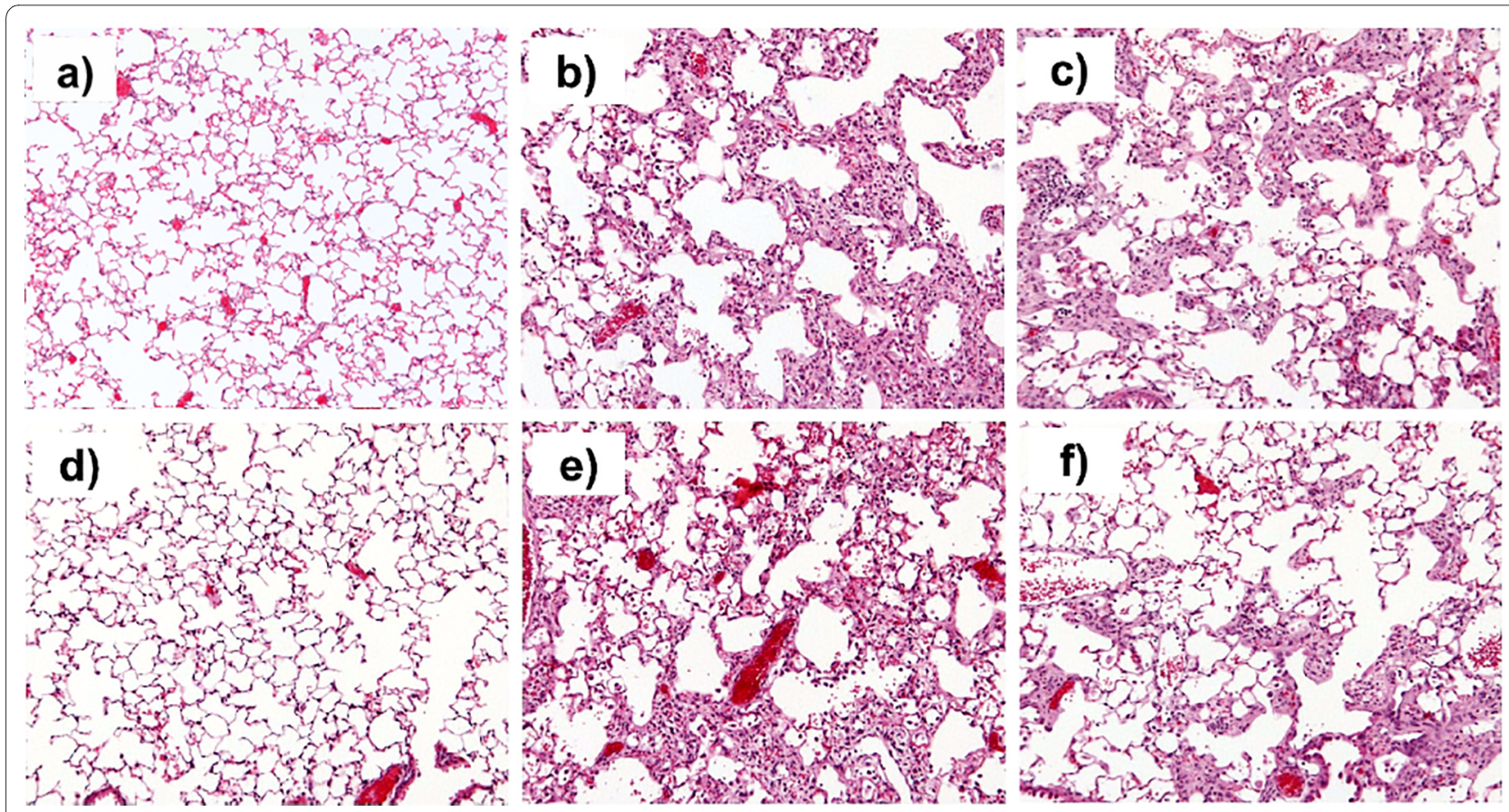

Figure 4 PDE4 inhibition attenuates tissue remodeling at late stage fibrosis. Representative images of lungs of healthy controls treated with vehicle $(a, d)$ and of mice suffering from fibrosis and treated either with vehicle $(b, e)$ or cilomilast $(c, f)$ at days $14(a, b, c)$ and $24(d, e, f)$ after bleomycin administration. Hematoxilin-Eosin staining, magnification $\times 100$. 


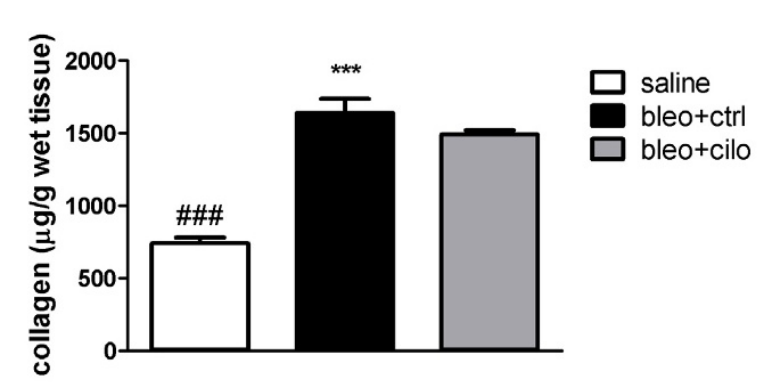

Figure 5 Effect of PDE4 inhibition on lung collagen content at late stage fibrosis. SIRCOL assay for the lungs of healthy controls treated with vehicle ("saline") and in mice suffering from fibrosis and treated either with vehicle ("bleo+ctrl") or cilomilast ("bleo+cilo") at day 24 after bleomycin administration. Values are presented as means $\pm \mathrm{SEM}, \mathrm{n}=4 .{ }^{*}$ saline vs. bleo+ctrl $\left({ }^{* *} \mathrm{p}<0.001\right)$, \# saline vs. bleo+cilo (\#\#\# $\mathrm{p}<0.001)$

animals that received cilomilast demonstrated higher lung compliance and lower fibrosis score. As the infiltration of inflammatory cells into the interstitium might also contribute to impairment of the lung function we believe that the significant improvement in compliance at day 14 results from more effective suppression of interstitial inflammation at this time point compared to late remodeling stage at day 24. Treatment with PDE4 inhibitor also tended to reduce lung collagen accumulation, as was shown by total collagen assay and Masson's trichrome staining, particularly at day 14 after bleomycin administration. In contrast, no significant effects were seen at mRNA level of COL(I) 1 , which might result from contribution of other collagen types' expression. Similarly, no effect of cilomilast treatment on TGF- $\beta 1$ expression was observed.

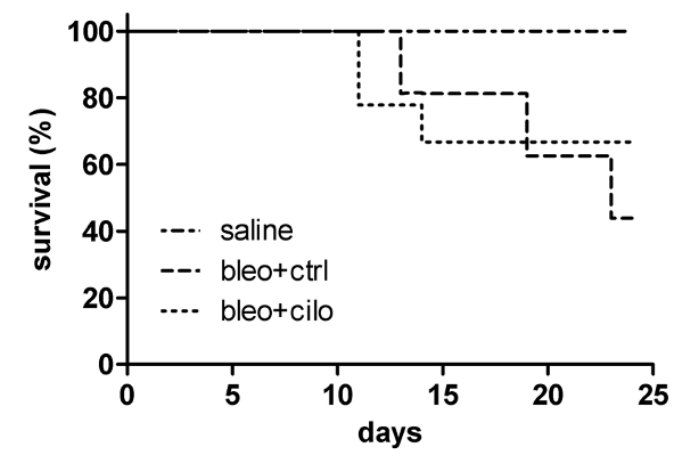

Figure 6 Effect of PDE4 inhibition on survival. Healthy controls treated with vehicle ("saline") and mice suffering from fibrosis and treated either with vehicle ("bleo+ctrl") or cilomilast ("bleo+cilo") followed up for 24 days after bleomycin instillation. Kaplan-Meier curves, $\mathrm{n}=9$.
Based on our observations and the results of other authors we suppose that inhibition of PDE4 affects both general aspects of $\mathrm{PF}$, namely inflammation and tissue remodeling itself. At first, PDE4 inhibition suppresses tissue fibrosis by partial elimination of pro-fibrotic environment, for instance by suppression of inflammatory cells infiltration, downregulation of TNF- $\alpha$ and stimulation of IL-6 expression shown in the present work. TNF- $\alpha$ secreted by macrophages $[2,36]$ is a direct mitogen for lung fibroblasts [37] and its inhibition can be alone sufficient to attenuate PF [38]. Moreover, it was shown that PDE4 itself is necessary for TNF- $\alpha$ production and development of inflammatory response [15,25]. Secondly, there are evidences implying that PDE4 inhibitors are also able to act through inflammation-independent way. For instance, it was repetitively shown that elevation of cAMP level results in inhibition of lung fibroblast proliferation, migration, transition to myofibroblasts and collagen production [11-13]. It was also shown that PKA can directly inhibit Raf thereby affecting the RAS/RAF/MEK/ ERK pathway. Details of this interaction are not fully understood, however at least three possible mechanisms are suggested [39]. Our group has also previously demonstrated that cAMP raised by PDE3/4 inhibitor tolafentrine inhibits enhanced migration of PASMCs derived from vessels of rats suffering from pulmonary hypertension [17]. All together these data suggest that the effects observed in present study might be accounted to several independent actions of the PDE4 inhibitor, affecting both inflammatory process and the effector cells at the site of ongoing fibrosis.

\section{Conclusions}

PDE4 inhibition by cilomilast attenuates bleomycininduced pulmonary fibrosis in mice. Primarily, cilomilast exerts its beneficial effects via reduction of inflammatory response, although it does not significantly affect neutrophils release. Cilomilast treatment also moderately affects tissue remodeling at late fibrosis stage. This seems to be the consequence of its anti-inflammatory action, although direct effect on tissue remodeling via inflammation-independent mechanism is highly possible.

\section{Additional material}

Additional file 1 Effect of PDE4 inhibition on lung collagen deposition at late stage fibrosis. Representative images of lungs of healthy controls $(a, d)$ and of mice suffering from fibrosis and treated either with vehicle $(b, e)$ or cilomilast $(c, f)$ at days $14(a, b, c)$ and $24(d, e, f)$ after bleomycin administration. Masson's trichrome staining, magnification $\times 100$.

Additional file 2 Effect of PDE4 inhibition on lung collagen expression at late stage fibrosis. mRNA levels of $\mathrm{COL}(\mathrm{I}) \mathrm{a} 1$ in healthy controls ("saline") and in mice suffering from fibrosis and treated either with vehicle ("bleo+ctrl") or cilomilast ("bleo+cilo") at days 14 and 24 after bleomycin administration. RT-qPCR data are normalized to $\beta$-actin expression and presented as $\triangle$ Ct values \pm SEM, $n=4$ 
Additional file 3 Effect of PDE4 inhibition on late stage fibrosis. mRNA levels of TGF- $\beta 1$ in healthy controls ("saline") and in mice suffering from fibrosis and treated either with vehicle ("bleo+ctrl") or cilomilast ("bleo+cilo") at days 14 and 24 after bleomycin administration. RT-qPCR data are normalized to $\beta$-actin expression and presented as $\Delta C$ t values \pm SEM, $n=4$.

\section{Competing interests}

SU received a doctoral stipendium from Altana Pharma AG. RTS received lecture fees from Encysive and Bayer-Schering and research grants from Ergonex, Encysive, Actelion and Bayer-Schering.

\section{Authors' contributions}

SU carried out experimental work, data analysis and manuscript drafting. RD assisted in animal experiments and BALF cell count. SSP and RTS assisted in data analysis, participated in study design and reviewed the manuscript. HMA assisted in manuscript revision. AG, NW and HAG participated in study design. RV, FG and WS participated in study coordination. All authors read and approved the manuscript.

\section{Acknowledgements}

The authors kindly thank laboratory of Prof. Dr. J. Lohmeyer for providing differential BALF cell count facilities and Nycomed Europe GmbH for providing cilomilast. This work was supported by the "Deutsche Forschungsgemeinschaft", KFO 118, project TP 7 and by the European Commission under the Sixth Frame Work Program [contract No. LSHM-CT-2005-018725, PULMOTENSION].

\section{Author Details}

${ }^{1}$ University of Giessen, Department of Internal Medicine, Giessen, Germany and ${ }^{2}$ Max-Planck-Institute for Heart and Lung Research, Department of Lung Development and Remodeling, Bad Nauheim, Germany

Received: 15 September 2009 Accepted: 5 May 2010 Published: 5 May 2010

\section{References}

1. Meltzer EB, Noble PW: Idiopathic pulmonary fibrosis. Orphanet J Rare Dis 2008, 3:8.

2. Piguet PF, Ribaux C, Karpuz V, Grau GE, Kapanci Y: Expression and localization of tumor necrosis factor-alpha and its mRNA in idiopathic pulmonary fibrosis. Am J Pathol 1993, 143:651-655.

3. Kline JN, Schwartz DA, Monick MM, Floerchinger CS, Hunninghake GW: Relative release of interleukin-1 beta and interleukin-1 receptor antagonist by alveolar macrophages. A study in asbestos-induced lung disease, sarcoidosis, and idiopathic pulmonary fibrosis. Chest 1993, 104:47-53.

4. Takizawa H, Satoh M, Okazaki H, Matsuzaki G, Suzuki N, Ishii A, Suko M, Okudaira H, Morita Y, Ito K: Increased IL-6 and IL-8 in bronchoalveolar lavage fluids (BALF) from patients with sarcoidosis: correlation with the clinical parameters. Clin Exp Immunol 1997, 107:175-181.

5. Chaudhary NI, Schnapp A, Park JE: Pharmacologic differentiation of inflammation and fibrosis in the rat bleomycin model. Am J Respir Crit Care Med 2006, 173:769-776.

6. Lugnier C: Cyclic nucleotide phosphodiesterase (PDE) superfamily: a new target for the development of specific therapeutic agents. Pharmacol Ther 2006, 109:366-398,

7. McLaughlin MM, Cieslinski LB, Burman M, Torphy TJ, Livi GP: A low-Km, rolipram-sensitive, CAMP-specific phosphodiesterase from human brain. Cloning and expression of CDNA, biochemical characterization of recombinant protein, and tissue distribution of mRNA. J Biol Chem 1993, 268:6470-6476.

8. Wang P, Wu P, Ohleth KM, Egan RW, Billah MM: Phosphodiesterase 4B2 is the predominant phosphodiesterase species and undergoes differential regulation of gene expression in human monocytes and neutrophils. Mol Pharmacol 1999, 56:170-174.

9. Martin-Chouly CA, Astier A, Jacob C, Pruniaux MP, Bertrand C, Lagente V: Modulation of matrix metalloproteinase production from human lung fibroblasts by type 4 phosphodiesterase inhibitors. Life Sci 2004, 75:823-840.

10. Barnes AP, Livera G, Huang P, Sun C, O'Neal WK, Conti M, Stutts MJ, Milgram SL: Phosphodiesterase 4D forms a cAMP diffusion barrier at the apical membrane of the airway epithelium. J Biol Chem 2005, 280:7997-8003

11. Liu X, Ostrom RS, Insel PA: cAMP-elevating agents and adenylyl cyclase overexpression promote an antifibrotic phenotype in pulmonary fibroblasts. Am J Physiol Cell Physiol 2004, 286:C1089-1099.

12. Kohyama T, Liu X, Kim HJ, Kobayashi T, Ertl RF, Wen FQ, Takizawa H, Rennard SI: Prostacyclin analogs inhibit fibroblast migration. Am J Physiol Lung Cell Mol Physiol 2002, 283:L428-432.

13. Kolodsick JE, Peters-Golden M, Larios J, Toews GB, Thannickal VJ, Moore BB: Prostaglandin E2 inhibits fibroblast to myofibroblast transition via E. prostanoid receptor 2 signaling and cyclic adenosine monophosphate elevation. Am J Respir Cell Mol Biol 2003, 29:537-544.

14. Souness JE, Griffin M, Maslen C, Ebsworth K, Scott LC, Pollock K, Palfreyman MN, Karlsson JA: Evidence that cyclic AMP phosphodiesterase inhibitors suppress TNF alpha generation from human monocytes by interacting with a 'low-affinity' phosphodiesterase 4 conformer. Br J Pharmacol 1996, 118:649-658.

15. Jin SL, Conti M: Induction of the cyclic nucleotide phosphodiesterase PDE4B is essential for LPS-activated TNF-alpha responses. Proc Natl Acad Sci USA 2002, 99:7628-7633.

16. Rennard SI, Schachter N, Strek M, Rickard K, Amit O: Cilomilast for COPD: results of a 6-month, placebo-controlled study of a potent, selective inhibitor of phosphodiesterase 4. Chest 2006, 129:56-66.

17. Pullamsetti S, Krick S, Yilmaz H, Ghofrani HA, Schudt C, Weissmann N, Fuchs B, Seeger W, Grimminger F, Schermuly RT: Inhaled tolafentrine reverses pulmonary vascular remodeling via inhibition of smooth muscle cell migration. Respir Res 2005, 6:128.

18. Kohyama T, Liu X, Zhu YK, Wen FQ, Wang HJ, Fang Q, Kobayashi T, Rennard SI: Phosphodiesterase 4 inhibitor cilomilast inhibits fibroblastmediated collagen gel degradation induced by tumor necrosis factoralpha and neutrophil elastase. Am J Respir Cell Mol Biol 2002, 27:487-494.

19. Griswold DE, Webb EF, Badger AM, Gorycki PD, Levandoski PA, Barnette MA, Grous M, Christensen S, Torphy TJ: SB 207499 (Ariflo), a second generation phosphodiesterase 4 inhibitor, reduces tumor necrosis factor alpha and interleukin-4 production in vivo. $J$ Pharmacol Exp Ther 1998, 287:705-711.

20. Wollin L, Bundschuh DS, Wohlsen A, Marx D, Beume R: Inhibition of airway hyperresponsiveness and pulmonary inflammation by roflumilast and other PDE4 inhibitors. Pulm Pharmacol Ther 2006, 19:343-352.

21. Corbel M, Germain N, Lanchou J, Molet S, R e Silva PM, Martins MA, Boichot $\mathrm{E}$, Lagente $\mathrm{V}$ : The selective phosphodiesterase 4 inhibitor RP 73-401 reduced matrix metalloproteinase 9 activity and transforming growth factor-beta release during acute lung injury in mice: the role of the balance between tumor necrosis factor-alpha and interleukin-10. $J$ Pharmacol Exp Ther 2002, 301:258-265.

22. Videla S, Vilaseca J, Medina C, Mourelle M, Guarner F, Salas A, Malagelada $J R$ : Selective inhibition of phosphodiesterase-4 ameliorates chronic colitis and prevents intestinal fibrosis. J Pharmacol Exp Ther 2006, 316:940-945.

23. Alejandre-Alcazar MA, Kwapiszewska G, Reiss I, Amarie OV, Marsh LM, Sevilla-Pérez J, Wygrecka M, Eul B, Köbrich S, Hesse M, Schermuly RT, Seeger W, Eickelberg O, Morty RE: Hyperoxia modulates TGF-beta/BMP signaling in a mouse model of bronchopulmonary dysplasia. Am J Physiol Lung Cell Mol Physiol 2007, 292:L537-549.

24. Ashcroft T, Simpson JM, Timbrell V: Simple method of estimating severity of pulmonary fibrosis on a numerical scale. J Clin Pathol 1988, 41:467-470.

25. Jin SL, Lan L, Zoudilova M, Conti M: Specific role of phosphodiesterase 4B in lipopolysaccharide-induced signaling in mouse macrophages. J Immunol 2005, 175:1523-1531.

26. Ma D, Wu P, Egan RW, Billah MM, Wang P: Phosphodiesterase 4B gene transcription is activated by lipopolysaccharide and inhibited by interleukin-10 in human monocytes. Mol Pharmacol 1999, 55:50-57.

27. Manning CD, Burman M, Christensen SB, Cieslinski LB, Essayan DM, Grous M, Torphy TJ, Barnette MS: Suppression of human inflammatory cell function by subtype-selective PDE4 inhibitors correlates with inhibition of PDE4A and PDE4B. Br J Pharmacol 1999, 128:1393-1398.

28. Abrahamsen H, Baillie G, Ngai J, Vang T, Nika K, Ruppelt A, Mustelin T, Zaccolo M, Houslay M, Tasken K: TCR- and CD28-mediated recruitment of phosphodiesterase 4 to lipid rafts potentiates TCR signaling. $J$ Immunol 2004, 173:4847-4858. 
29. Lesur OJ, Mancini NM, Humbert JC, Chabot F, Polu J-M: Interleukin-6, Interferon-gamma, and phospholipid levels in the alveolar lining fluid of human lungs: profiles in coal worker's pneumoconiosis and idiopathic pulmonary fibrosis. Chest 1994, 106:407-413.

30. Cailes JB, O'Connor C, Pantelidis P, Southcott AM, Fitzgerald MX, Black CM, du Bois RM: Neutrophil activation in fibrosing alveolitis: a comparison of lone cryptogenic fibrosing alveolitis and systemic sclerosis. Eur Respir J 1996, 9:992-999.

31. Obayashi Y, Yamadori I, Fujita J, Yoshinouchi T, Ueda N, Takahara J: The role of neutrophils in the pathogenesis of idiopathic pulmonary fibrosis. Chest 1997, 112:1338-1343.

32. Ariga M, Neitzert B, Nakae $S$, Mottin G, Bertrand C, Pruniaux MP, Jin SL, Conti M: Nonredundant function of phosphodiesterases $4 \mathrm{D}$ and $4 \mathrm{~B}$ in neutrophil recruitment to the site of inflammation. J Immuno/ 2004 173:7531-7538

33. Izbicki G, Segel MJ, Christensen TG, Conner MW, Breuer R: Time course of bleomycin-induced lung fibrosis. Int J Exp Pathol 2002, 83:111-119.

34. Denis M: Interleukin- 6 in mouse hypersensitivity pneumonitis: changes in lung free cells following depletion of endogenous IL- 6 or direct administration of IL-6. J Leukoc Biol 1992, 52:197-201.

35. Prabhakar U, Lipshutz D, Bartus JO, Slivjak MJ, Smith EF, Lee JC, Esser KM: Characterization of CAMP-dependent inhibition of LPS-induced TNF alpha production by rolipram, a specific phosphodiesterase IV (PDE IV) inhibitor. Int I Immunopharmacol 1994, 16:805-816.

36. Losa Garcia JE, Rodriguez FM, Martin de Cabo MR, Garcia Salgado MJ, Losada JP, Villaron LG, Lopez AJ, Arellano JL: Evaluation of inflammatory cytokine secretion by human alveolar macrophages. Mediators Inflamm 1999, 8:43-51.

37. Battegay EJ, Raines EW, Colbert T, Ross R: TNF-alpha stimulation of fibroblast proliferation. Dependence on platelet-derived growth factor (PDGF) secretion and alteration of PDGF receptor expression. Immunol 1995, 154:6040-6047.

38. Piguet $\mathrm{PF}$, Vesin $\mathrm{C}$ : Treatment by human recombinant soluble TNF receptor of pulmonary fibrosis induced by bleomycin or silica in mice. Eur Respir J 1994, 7:515-518.

39. Dumaz N, Marais R: Integrating signals between CAMP and the RAS/ RAF/MEK/ERK signalling pathways. FEBS Journal 2005, 272:3491-3504

\section{Pre-publication history}

The pre-publication history for this paper can be accessed here: http://www.biomedcentral.com/1471-2466/10/26/prepub

doi: 10.1186/1471-2466-10-26

Cite this article as: Udalov et al., Effects of phosphodiesterase 4 inhibition on bleomycin-induced pulmonary fibrosis in mice BMC Pulmonary Medicine 2010, 10:26

Submit your next manuscript to BioMed Central and take full advantage of:

- Convenient online submission

- Thorough peer review

- No space constraints or color figure charges

- Immediate publication on acceptance

- Inclusion in PubMed, CAS, Scopus and Google Scholar

- Research which is freely available for redistribution

Submit your manuscript at www.biomedcentral.com/submit
C) Biomed Central 